The largest medical malpractice award in Canada is "an isolated case" and will not set a precedent for similar malpractice cases in the future, says the president of the Society of Obstetricians and Gynaecologists of Canada (SOGC).

In a recent decision, the Ontario Court of Appeal upheld an Ontario Superior Court decision that will see a Smith Falls family receive more than $\$ 10$ million to compensate for the 1983 delivery of their daughter, who suffered brain damage at birth because of a lack of oxygen. The daughter, now a nonverbal quadriplegic with cerebral palsy, had her shoulder lodged in the birth canal after induction. Physicians eventually freed her after about $15 \mathrm{~min}$ - utes, but she was born limp and not breathing.

Ontario Superior Court Justice Denis Power ruled that the injuries the baby suffered were the result of negligence on the part of the physicians. He noted that the physicians should have recognized that the pregnancy was high risk because of the presence of gestational diabetes and should have referred the mother to an obstetrics specialist.

The family physicians involved in the case, Dr. Brian J. Penny and Dr. Greg Healey, and the managers at the Canadian Medical Protective Association (CMPA), have 60 days from the time of the Sept. 10 ruling to file an appeal.

"This decision won't change the way we practise medicine," said SOGC President Dr. Gerry Stanimir, a Montreal-based obstetrician-gynecologist. "As a group of physicians, we practise evidence-based medicine and deliver 80000 babies a year. One case will not change the way we practice medicine."

Stanimir says the physicians involved performed to the best of their ability and met the standards of practise at the time.

"It was a difficult case [delivery]," said Stanimir, noting it was an 11-pound baby whose mother had been diagnosed with gestational diabetes. "They followed the standards of care and did perform the best they could, given the circumstances at the time."

The CMPA declined to comment on the case. - Louise Gagnon, Ottawa

Waiting Times

\title{
Manitoba to fast-track less critical emergency patients
}

Manitoba has implemented a fast-lane system to keep less critical patients moving through the emergency department more rapidly, making way for more urgent cases.

The new fast-lane system, which is being piloted at the Health Sciences Centre, Manitoba's largest teaching hospital, will speed up service for the largest group of patients, those assessed as Level III and IV. These patients typically have relatively minor ailments such as lacerations, infections, minor headaches, muscle strains, vomiting and diarrhea.

At HSC and St. Boniface hospitals nurse practitioners will treat most of the fast-tracked patients.

The system was developed by $\therefore$ a task force of nurses, physicians and hospital administrators after a year-long review of patient charts and an investigation of cases where patients died while waiting.

Manitoba is also spending about $\$ 1.5$ million on a new computer system to track pa- tients and plot treatment to ensure they are discharged at the earliest possible opportunity.

However, the Canadian Association of Emergency Physicians (CAEP) says fast-tracking may not address the central cause of emergency department overcrowding.

"Emergency department overcrowding is due to too many inpatients occupying stretchers, it's not due to lowlevel cases in the waiting rooms," said CAEP president Dr. Andrew Affleck. "[Inpatients] are the [ones] who are waiting and they are the patients whose care is compromised."

Jan Currie, vice-president of the Winnipeg Regional Health Authority, said the task force found it wasn't the number of emergency beds per se that creates a backlog in Level II cases. "The length of stay upstairs is the real issue," said Currie. "If we can lower the length of stay, then we will be more efficient."

Affleck applauded these mea-

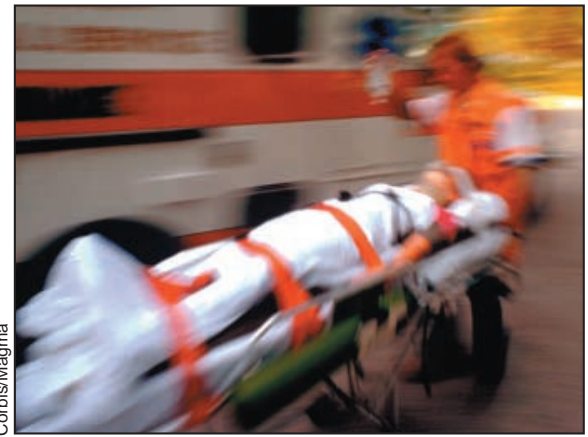

Fast-lane system gets the largest group of patients moving.

sures but warned that they will not speed service to more serious Level II cases, the ones that are typically at most risk of becoming medical incidents. These cases require patients to be admitted to hospital but remain in the emergency department for observation and treatment. Most of Canada's emergency departments simply do not have the capacity to handle the current volume of those requiring inpatient treatment, Affleck added. Dan Lett, Winnipeg 